\title{
Psychological aspects of information seeking on the Internet
}

\author{
Adam Joinson \\ Institute of Educational Technology, The Open University, Milton Keynes, \\ MK7 6AA \\ A.N.Joinson@open.ac.uk
}

\section{Phil Banyard}

The Department of Social Sciences, Nottingham Trent University, Burton Street, Nottingham NG1 4BU

phil.banyard@ntu.ac.uk

Two studies are presented that investigate information seeking behaviour on the Internet. In Study One, soccer fans' information seeking on the World Wide Web (WWW) is investigated. In Study Two, access rates to a cancer information website are analysed. It is tentatively argued that there is a tendency for people to access information more commonly avoided in 'real life', although in the case of football fans, the tendency to 'bask in reflected glory' remains when online, while cutting off reflected failure is minimised. Implications for understanding and researching psychological processes of web browsing behaviour are discussed.

\section{Introduction}

A new field of enquiry, 'cyberpsychology' or 'the psychology of the Internet', has begun taking form over the last couple of years (although arguably it dates back further with psychological research on telephone - and computer-mediated communication). With the recent launch of two journals (CyberPsychology and Behavior and The Journal of On-line Behavior) and a number of books (Gackenbach, 1998; Wallace, 1999), the psychological processes involved in Internet behaviour is increasingly becoming a topic of academic research.

In keeping with its roots in 'traditional' work on computer-mediated communication, the majority of cyberpsychological research is directed at communication over the Internet. For instance, recent papers have focused on self-disclosure in computermediated communication (CMC) (Joinson, 2001), health care and CMC (Budman, 2000), gender differences in 'smiley' (or emoticon) use (Wolf, 2000) and the development of norms in CMC groups (Postmes et al., 2000).

Other focuses of work in this area include the psychological impact of Internet use (e.g. addiction (Griffiths, 1998) or social isolation and depression (Kraut et al., 1998)), the use of the Internet to conduct psychological research and assessment (Birnbaum, 2000; Buchanan, 2000; Joinson and Buchanan, 2001; Joinson, 1999) and 'deviant' behaviour during Internet use (e.g. identity manipulation).

However, despite its importance in popularising the Internet outside academic and military circles, the psychological processes associated with information seeking (or 'browsing') on the World Wide Web (WWW) has received scant attention from 
psychological researchers. Of the few studies published that do not deal exclusively with its use as a research tool, the majority deal with the evaluation of websites, or in rare cases the use of search engines and or navigation strategies from a humancomputer interaction perspective. This pattern is repeated in medical research, with the majority of work that deals with the Web focusing almost exclusively on the content of the websites rather than users' behaviour in accessing information.

This omission of the Web from the body of developing knowledge of social behaviour on the Internet is problematic because the Web drove much of the development on the Internet in terms of usage and application/innovation. While the almost limitless amount of information available on the Web is often touted as one of the main reasons to access the Internet, relatively little is known about the psychological processes that underpin the seeking of that information (see Thelwell, 2001).

In particular, we are concerned with differences and similarities between patterns of information seeking in 'real life' and on the Internet. There is a well-established body of research in computer-mediated communication to suggest that the medium used for person-to-person communication has a significant effect on, for instance, selfdisclosure (Joinson, 2001) and affiliation within an interaction (Walther, 1996). The main causes for these differences seem to be the perceived and real anonymity of communication over the Internet (particularly visual anonymity - not being able to see the other person), the linguistic techniques used in CMC (i.e. paralanguage like emoticons) and the norms within an online environment. It is unclear whether web behaviour is similarly disinhibited. The two studies reported here begin a tentative process of studying the psychological processes that underpin web information seeking.

\section{Study One: soccer fans on the WWW}

Fanship was chosen as the focus of Study One because it allows for clear predictions about information seeking behaviour in real life. For many fans, an association with a favoured team forms an important aspect of their identity. By incorporating an association with a favoured team into the self-concept, that person is also party to the foibles of their favoured team's subsequent performances. The benefits of fanship are generally thought to be grounded in a tendency to 'bask in reflected glory' (BIRGing), where a person publicises their association with a successful other. For instance, in one study (Cialdini et al., 1976), it was found that significantly more people wore the college football team sweatshirt the Monday after a win than the Monday after a loss. Furthermore, they found that fans used the pronoun we more frequently after a win than after they (the team) lost.

If fanship has benefits when the team is successful, it should also have costs when the team is unsuccessful. Poor performances by a team to which one is closely associated should have a negative impact on the evaluation of fans, and those fans' own selfevaluation. Indeed, it has been found that poor performances by a college basketball team have a negative impact on both the mood and self-esteem of fans, and their optimism for both self and team future performance (Hirt et al., 1992).

\footnotetext{
${ }^{1}$ The results of Study One were originally reported in Joinson (2000)
} 
Because fans are not willing to stop supporting a team once an association has been formed, fans must use impression management strategies when faced with a poor performance. Snyder, Higgins and Stucky $(1983)^{15}$ used the term 'cutting off reflected failure' (CORFing) to describe how individuals avoid the negative evaluations that follow being associated with a negatively valued other. The main CORFing strategy is to reduce the association between the self and the negatively valued item, for example by claiming a weaker association with a negative group than actually exists. An alternative CORFing strategy, especially if the audience is internal, is to avoid information about a favoured team following a defeat.

The aim of this study is to examine the information seeking of soccer fans on the World Wide Web. If web information sources are used for self-enhancement purposes, it would be expected that access rates would increase following a win. Conversely, if web sources are a potential threat to fans' self-image following a defeat, it would be expected that access rates would fall. However, in light of the apparent willingness of people to access on the Web information avoided in real life, the number of accesses are not predicted to fall following a defeat.

\section{Method}

\section{Methodological overview and design}

The primary measure of information searching was the raw level of activity, in the form of accesses per day. This measure includes accesses to all pages, rather than simply to the main 'homepage'. In August 1994 an e-mail message was sent to the owners of FA Premiership web pages asking for their co-operation. Of those that replied, the Manchester City and Liverpool web pages already collected the number of raw accesses, so they were chosen for the study. The owner of the Everton fanzine provided two months figures, and began collecting data in February (see below for dates).

There were two conditions used in the study. The first was the three level (win, loss and draw) between-subjects factor of the actual results the team achieved. The second condition was the two level (pre-result and post-result) within-subjects measure of timescale. For each result, the number of accesses before a result acted as the control, and the number of accesses after a specific result acted as the experimental condition.

\section{Materials}

On each day the owners of the fanzines collected the number of accesses to each team's web pages. For Manchester City the data ran from the start of November 1994 to May 8th 1995. For Liverpool the data ran from the start of the season (August 18th 1994) to January 5th 1995. The data for Everton ran through the whole of October and November, and then from February 16th 1995 to the beginning of May 1995.

Because at the time of the study most people had access to the Internet through their workplace, two measures were used. For the control, the number of accesses the last working day before a result was used. For the experimental number of accesses, the first working day after a result was used. Generally, if a match was on a Saturday, this 
meant that the control day was a Friday, and the experimental day was a Monday. Because the dependent variable (number of accesses) was measured both pre- and post-result, and a within-subjects design utilised, any tendency to either BIRG or CORF was not confounded with a general increase in activity as the Internet became more popular. That is, if a site became more popular (and this coincided with a winning run), the use of a control ensured that the baseline level of activity increased accordingly.

The Christmas programme was excluded from the analysis because of the low level of accesses over the Christmas and New Year period. This led to a total of 76 results for analysis: 30 victories, 19 draws and 27 defeats. There were 25 Liverpool results (14 wins, 5 defeats, 6 draws), 19 Everton results ( 6 wins, 9 defeats, 4 draws), and 32 Manchester City results (10 wins, 13 defeats, 9 draws).

\section{Results and discussion}

The mean level of accesses for each team's homepage across the two conditions is shown in Table 1. The data from each team's website was initially analysed separately to examine whether the same pattern of activity existed for each. A series of two-way, mixed design (result $x$ timescale) ANOVAs yielded a no effect of the betweensubjects variable (result) or the within-subjects variable (timescale) for each of the teams. The interaction between the result achieved by the team and whether the measure was pre or post that result was significant for Everton $(\underline{F}(2,16)=4.57$, $\underline{\mathrm{p}}<.05)$ and Manchester City $(\underline{\mathrm{F}}(2,29)=5.92, \underline{\mathrm{p}}<.01)$, and marginally significant for Liverpool $(\underline{\mathrm{F}}(2,22)=3.04, \underline{p}=.068)$.

Table 1. Mean number of 'hits' across results by team

\begin{tabular}{llccc}
\hline & \multicolumn{4}{c}{ Time scale } \\
\cline { 2 - 5 } & \multicolumn{3}{c}{ Pre-result } & \multicolumn{2}{c}{ Post-result } \\
\cline { 2 - 5 } & Mean & Std & Mean & Std \\
\hline Man City & & & \\
Win & $442.5^{*}$ & 189.9 & $714.7 *$ & 358.9 \\
Draw & 612.3 & 289.2 & 589.0 & 203.2 \\
Defeat & 564.8 & 320.9 & 524.7 & 247.5 \\
\hline Everton & & & & \\
Win & 278.5 & 214.6 & 339.2 & 191.3 \\
Draw & 393.0 & 269.6 & 229.5 & 131.9 \\
Defeat & 316.8 & 248.7 & 267.3 & 234.7 \\
\hline Liverpool & & & \\
Win & $773.5^{*}$ & 291.6 & $1041.9 *$ & 505.4 \\
Draw & 1018.7 & 367.1 & 970.5 & 441.9 \\
Defeat & 812.0 & 306.9 & 870.8 & 357.7 \\
\hline
\end{tabular}

Note: $*$ = significant difference $(5 \%)$ between pre and post accesses levels for each repeated measure. 
A combined (across all teams) 2 X 2 ANOVA (Result $\mathrm{x}$ Timescale) showed a significant interaction between the result the team achieved and whether the measure was pre or post that result on the number of accesses $(\underline{F}(2,73)=12.6, \underline{p}<.001)$. This interaction is illustrated in Figure 1. Simple effects analyses found that the level of activity was significantly higher post victory than before a victory $(p<.05)$, but not significantly different after a defeat or draw compared to before a defeat or draw.

Figure 1. Mean number of 'hits' before and after a result (combined across all three teams)

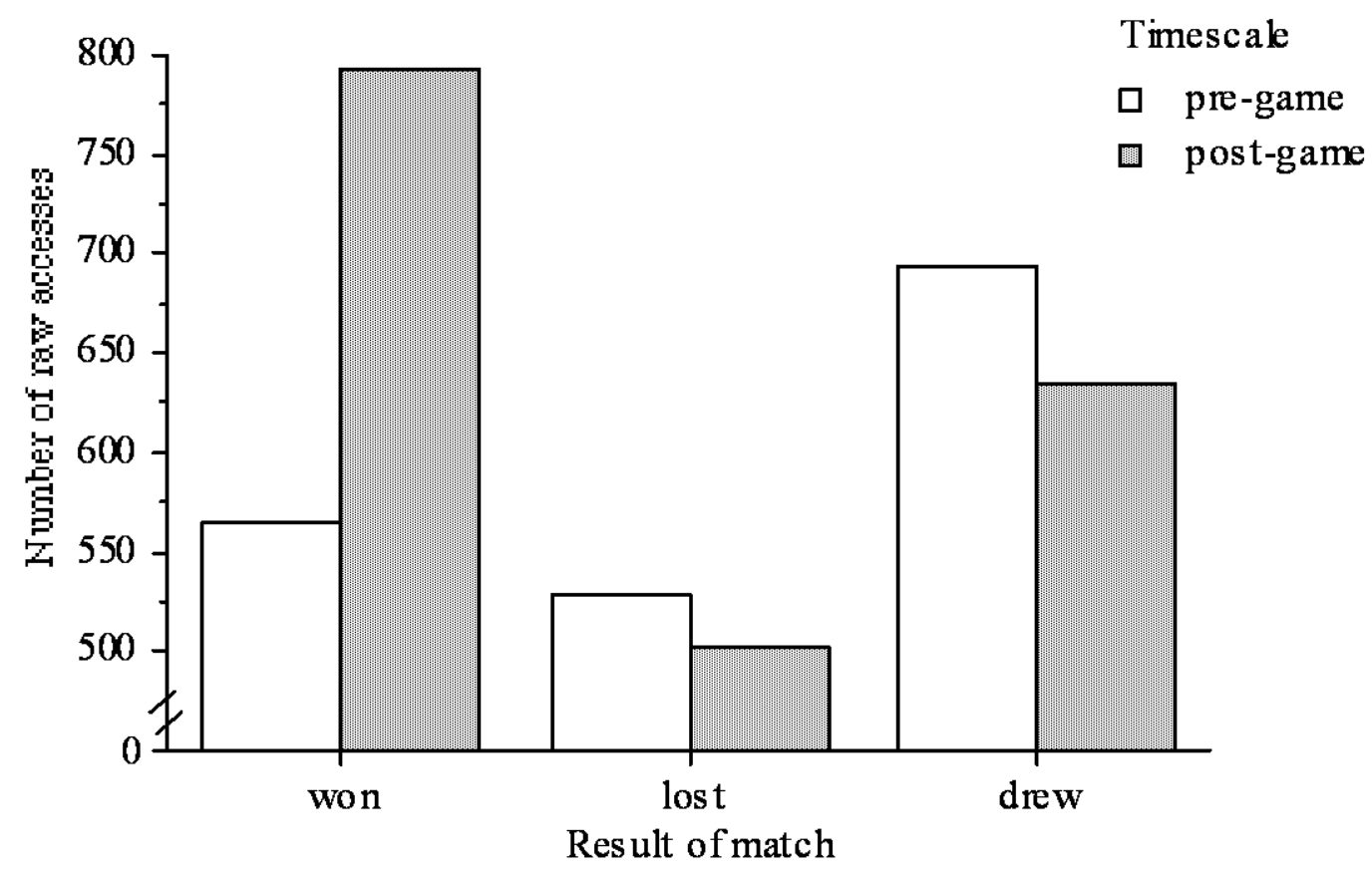

As expected, the number of accesses to football fanzines on the Internet increased the first working day after a win compared with the last working day before a win. Information seeking on the Internet may therefore be motivated by self-enhancement concerns. There were no significant differences between the first working day after a losing performance and the last working day before a loss. This suggests that the need to protect one's self-image by 'cutting off reflected failure' does not influence information seeking on the Internet. This pattern of results supports the notion that people are more willing to seek potentially threatening information on the Internet than in 'real life'.

Interestingly, levels of accesses before a draw were (non-significantly) higher than levels before either a victory or defeat, perhaps because these games were between teams more closely matched (hence the draw), and thus generated greater interest in potentially diagnostic information. 


\section{Study Two: seeking cancer information on the WWW}

The Internet is becoming an important source of health information. A search by the present authors for the term 'cancer' in early 2001 yielded 6,680,000 results using the search engine www.google.com. However, our understanding of the motives for people accessing cancer sites are not well known. For example, people might wish to gain more information about a personal condition with a view to self-diagnosis, they might wish to gain more information to consider suitable treatments or prognosis, or they might wish to make contacts with people in a similar condition to themselves. In some cases, they may well be relatives or friends of people diagnosed with cancer. It is even possible that people accessing a health information site do not have any illness, but are seeking preventative information about a range of potential ailments.

It is also possible that psychological factors are involved in the information seeking behaviour of health site users. For instance, it is common for people to avoid or misremember threatening information (Taylor, 1989). This is particularly the case if health information is seen as personally relevant (Sherman et al., 2000). Males also tend to avoid health check-ups because attending would show signs of physical vulnerability (Davies et al., 2000). However, it has long been argued that the Internet has a disinhibiting effect on users (Joinson, 1998), which may encourage users to access information normally avoided (Joinson, 2000) or indeed to disclose more health-relevant information about themselves than they would face-to-face (Joinson, 2001).

However, although the disinhibiting effect of the Internet seems to be applicable to certain health behaviours (e.g. self-help groups), there is little evidence that people with unhealthy lifestyles are more likely to seek diagnostic and/or change-focused information on the Web than they would in 'real life'. For instance, a study of a staff health promotion site showed that users were predominantly those already exercising, rather than those either not taking any exercise or those contemplating taking more exercise than at present (Griffin et al., 2000). One possible step toward understanding the motivations of health-web users would be to compare access figures to a health site with a comparable 'real life' information source. The present study does precisely this: by comparing access data from a cancer website and a telephone helpline it is hoped that some clues toward understanding users motivations might be garnered.

Telephone helplines also provide an interactive resource for people who are seeking information or support. Telephone cancer helplines can provide emotional support (Broadstock and Borland, 1998), and research has shown that cancer helplines are also able to provide complex information to people with cancer and also to their family and friends (Morra et al., 1993). There is some evidence that use of helplines is selective, for example some cancer helplines are only used by a small proportion of the client group they are set up for (Broadstock and Hill, 1997), and a study of users to the Anti-Cancer Council of Victoria's Cancer Information Service found that a large proportion of callers either had breast cancer $(54 \%)$ or genito-urinary cancers $(18 \%)$ (Broadstock and Borland, 1998).

The present research examines the use of cancer telephone helplines and Internet sites. It was predicted that the pattern of information seeking about cancer on the Web would closely mirror prevalence in the UK population. This is because it is expected 
that the main users of a cancer information site on the Web would be those already diagnosed, or those seeking information about someone who has been diagnosed. A second prediction was that embarrassing or stigmatised cancers (e.g. testicular, prostate and lung cancers) will more closely match prevalence than the telephone helpline.

\section{Method}

The two sources of cancer information were the Cancer Research Campaign (CRC) 'Cancer Help' website (http://www.cancerhelp.org.uk/) and the CancerBACUP telephone helpline (0800 181199). Information on the number of calls to the telephone helpline, sub-divided by the site of the cancer (e.g. lung, breast), between April 1997 and March 1998 were collected by the experimenters. Similarly, the number of 'hits' (pages accessed) to each type of cancer on the CRC website between April 1997 and March 1998 was also collected. There were six fully 'live' cancer information sections during the whole of the data collection period, with others joining during the year. Only the six sub-sections live throughout the data collection period were analysed.

The rates per 100,000 population of newly diagnosed cases of cancer in England and Wales in 1997 (collected by the Office for National Statistics) were used as a baseline for the investigation.

\section{Results and discussion}

The percentage 'hits' (number of accesses to each page within a subsection) for the five most popular cancer sites on the World Wide Web, and the matching telephone helpline and prevalence data are shown in Table 2.

Table 2. WWW and telephone helpline 'hits' by cancer site

\begin{tabular}{lcccccc}
\hline & Breast & Lung & $\begin{array}{c}\text { Colon \& } \\
\text { Rectum }\end{array}$ & Prostate & $\begin{array}{c}\text { Non- } \\
\text { Hodgkins } \\
\text { Lymphoma }\end{array}$ & Testicular \\
\hline WWW hits (\% six sites) & 24.2 & 21.3 & 15.6 & 10.7 & 12.8 & 11.6 \\
Telephone (\% all enquiries) & 27.6 & 7.2 & 7.6 & 6.5 & $<1$ & 1.9 \\
Telephone (\% six sites) & 53.49 & 13.95 & 14.73 & 12.6 & 1.55 & 3.68 \\
Prevalence (\% all cancers) & 15.6 & 15.1 & 13.0 & 8.4 & 3.5 & 0.7 \\
Prevalence (\% six sites) & 27.71 & 26.82 & 23.09 & 14.92 & 6.22 & 1.24 \\
$\begin{array}{l}\text { Female prevalence (\% six } \\
\text { sites) }\end{array}$ & 27.72 & 9.73 & 11.03 & 0 & 2.79 & 0 \\
Male prevalence (\% six sites) & 0 & 17.11 & 12.16 & 14.93 & 3.36 & 1.17 \\
\hline
\end{tabular}

The correlation between prevalence in England and Wales and web/telephone enquiries was analysed using Pearson's correlation co-efficient. As predicted, the pattern of accesses on the Web more closely matched prevalence $(r=.81)$ than the pattern of telephone calls $(\mathrm{r}=.63)$. A difference score was calculated between 
web/telephone percentages and the prevalence, and the two scores compared using a ttest. The difference between WWW and actual prevalence (392.7) was significantly smaller than the difference between the telephone helpline and prevalence $(425.6, \mathrm{t}(5)$ $=-2.88, \mathrm{p}=.03)$.

Looking more closely at the data, it is clear that some cancers over-represented on the Web (e.g. prostate and cancer) may represent the gender imbalance in Internet usage. Similarly, with almost twice the number of men diagnosed with lung cancer than women ( 81.6 vs. 46.4 per 100,000), the over-representation of lung cancer may again be a facet of a gender imbalance in Internet use. However, the over-representation of breast cancer on both the Web and telephone helplines suggests that women are using the Web in substantial numbers to access information about cancer. The large overrepresentation of testicular cancer is of particular interest, suggesting that in this case browsing may be more curiosity driven rather than post-diagnosis. In light of the welldocumented problems in encouraging men to self-examine or even to report to a medical professional when in severe pain, that they might be more willing to access information on testicular cancer on the Web is encouraging.

The data reported here strongly suggests that the Web may be a particularly useful resource to the provision of cancer information to groups who may under-use current resources, specifically men with testicular cancer, and both genders seeking information about lung cancer. However, just as health promotion information requires consideration of the stage of change of the user for effective change, so information about illnesses needs to recognise the motives of the Internet user. It is our contention that, in the main, the cancer site we studied was primarily used by people who had been diagnosed with a specific cancer. However, the overrepresentation of testicular cancer suggests that for stigmatised cancers where clear preventative measures are available (e.g. self-examination), the users may well be motivated by prophylactic goals. The provision of health information on the Internet needs to recognise this distinction.

\section{General discussion}

Despite focusing on information seeking in two seemingly dissimilar domains, the studies reported above share some striking similarities. A first is methodological both rely on log files and site traffic to infer information seeking and actual levels of activity. Although there are some technical problems in assuming that 'hit' is roughly equal to activity (Goldberg, 1995), in the studies reported here the methodology seemed quite strong (Thelwell, 2001). A further similarity is that in both cases information seeking activity did indeed seem to follow patterns on the Web that would not be expected in more 'traditional' media. A final similarity is in the increasing professionalism of the Web. When the soccer study was first conducted in 1994-1995, no football clubs had official web pages, and only around half of all UK Premiership clubs had fan-led sites. The common mode of information dissemination was via USENET newsgroups. In 1999 Green (1999) reported than just 45\% of football clubs he questioned had official websites. In the Premiership the figure is 75\%. A quick check in 2001-2002 confirms that all current Premiership football clubs now have official websites. Similarly, the cancer website, although some years later, 
and sponsored by a well-known organisation, was primarily the work of a single individual based in a university. The site has now been professionally redesigned.

Most discussions about information seeking on the Internet tend to stress the need to validate the accuracy and source of information. While the aim of this paper is not to question this worthy ambition, for sports fans information seeking is also motivated by other factors - specifically the impression management activities of fans. This would seem to be a robust effect: End (2001) studied BIRGing and CORFing strategies on the Internet amongst NFL fans in the States. He found that fans use the bulletin boards to bask in reflected glory following a victory, and that the bulletin boards of successful teams were busier than those of unsuccessful teams across the time-span of his study. The psychological processes identified in Study One here would therefore seem to apply equally well to computer-mediated communication and web browsing.

\section{Information seeking on the Internet: a methodological note}

As noted, hits are not the most accurate way to monitor behaviour on a website. Indeed, they can, for exceptionally popular sites, actually be misleading (Goldberg, 1995). At the time the research was conducted, there was little alternative to a painstaking analysis of $\log$ files. However, the use of cookies and dynamic web content, backlinks and queries information suggests that web behaviour should be open to more detailed investigation (Thelwell, 2001). Of course, these techniques are site specific - if a user leaves your site, you will not necessarily know where they go to next.

Alongside this is the need to know more not just about the types of information people seek on the Internet (like the above two studies), which is presumed to be motivated in some form or other. But we also need to know more about human-computer interaction from a web behaviour viewpoint. For instance, experienced users may well judge the potential usefulness of a hyperlink based on its URL before clicking the link. Similarly, if one is accessing the Internet in a public (or accountable/monitored) way, you may be less likely to access potentially useful information, on say testicular cancer, from a dubious sounding website (e.g. http://www.feelyourballs.com/) than a seemingly more respectable source (e.g. http://www.stfellshospital.edu/balls/).

\section{Conclusions}

The results of the two studies suggest that information seeking on the Internet has certain similarities (e.g. BIRGing) and differences (e.g. compared to telephone helplines) to information seeking in broadly equivalent off-line behaviours. We hypothesise that this is because the act of information seeking is a product of the interaction between the target information, the strategies employed to search, the social environment in which the information is sought and the psychological implications of the information on the seeker. To an extent, the dearth of information on the psychology of web behaviour reflects the relative paucity of information gathered on website visitors, and additional methodological problems (e.g. network caches (Goldberg, 1995). However, as surveillance procedures improve (e.g cookies, logged dynamic page serving), so it should be possible to better understand web browsing behaviour (Thelwell, 2001). Unfortunately, increased surveillance may well 
fundamentally change the behaviour being recorded - for instance, increased accountability tends to reduce the level of disinhibited communication over the Internet (Joinson, 2001). We must be careful not to throw the behavioural baby out with the methodological bath water.

\section{References}

Birnbaum, M.H. (2000). Psychological experiments on the Internet. (ed.) San Diego: Academic Press.

Broadstock, M. and Borland, R. (1998). Using information for emotion-focused coping: cancer patients' use of a cancer helpline. British Journal of Health Psychology, 3 (4), 319-332.

Broadstock, M.J. and Hill, D. (1997). Evaluation and impact of promotion of a cancer helpline to cancer patients through their specialists. Patient Education and Counseling, 32 (3), 141-146.

Buchanan, T. (2000). Potential of the Internet for personality research. In: Birnbaum, M.H. (ed.) Psychological experiments on the Internet. San Diego: Academic Press, 121-140.

Budman S.H. (2000). Behavioral health care dot-com and beyond: computer-mediated communications in mental health and substance abuse treatment. American Psychologist, 55 (11), 1290-1300.

Cialdini, R.B., Borden, R.J., Thorne, A., Walker, M.R., Freeman, S. and Sloan, L.R. (1976). Basking in reflected glory: three (football) studies. Journal of Personality and Social Psychology, 34 (3), 366-375.

Davies, J., McCrae, B.P., Frank, J., Dochnahl, A., Pickering, T., Harrison, B., Zakrzewski, M. and Wilson, K. (2000). Identifying male college students' perceived health needs, barriers to seeking help, and recommendations to help men adopt healthier lifestyles. Journal of American College Health, 48 (6), 259-267.

End, C.M. (2001). An examination of NFL fans' computer mediated BIRGing. Journal of Sport Behavior 24(2), 162-181.

Gackenbach, J. (1998). Psychology and the Internet: intrapersonal, interpersonal and transpersonal implications. New York: Academic Press.

Goldberg, J. (1995). Why web usage statistics are (worse than) meaningless. www.cranfield.ac.uk/docs/stats/ (visited 16 February 2000).

Green, R. (1999). Football information services: fanzines, 'Match of the Day' and the modem. ASLIB Proceedings, 51(1), 20-29.

Griffin, C., Eves, F. and Cheng, K.K. (2000). Issues in promoting exercise using the World Wide Web. Paper presented at the British Psychological Society London Conference, Institute of Education, 20 December 2000.

Griffiths, M. (1998). Internet addiction: does it really exist? In: Gackenbach, J. (ed.) Psychology of the Internet. New York: Academic Press, 61-75.

Hirt, E.R., Zillman, D., Erickson, G.A. and Kennedy, C. (1992). Costs and benefits of allegiance: changes in fans' self-ascribed competencies after team victory versus team defeat. Journal of Personality and Social Psychology, 63 (5), 724-738.

Joinson, A.N. (1998). Causes and implications of disinhibited behaviour on the Net. In: Gackenbach, J. (ed.) Psychology of the Internet. New York: Academic Press, 43-60.

Joinson, A.N. (1999). Anonymity, disinhibition and social desirability on the Internet. Behavior Research Methods, Instruments and Computers, 31 (3), 433-438. 
Joinson, A.N. (2000). Information seeking on the Internet: a study of soccer fans on the WWW. CyberPsychology and Behavior, 3 (2), 185-191.

Joinson, A.N. (2001). Self-disclosure in computer-mediated communication: the role of self-awareness and visual anonymity. European Journal of Social Psychology, 31 (2), 177-192.

Joinson, A.N. and Buchanan, T. (2001). Doing educational research on the Web. In: Wolfe, C. (ed.). Learning and teaching on the World Wide Web. New York: Academic Press, 221-242.

Kraut, R., Patterson, M., Lundmark, V., Kiesler, S., Mukopadhyay, T. and Scherlis, W. (1998). Internet paradox - a social technology that reduces social involvement and psychological well-being? American Psychologist, 53 (9), 1017-1031.

Morra, M., Bettinghaus, E., Marcus, A., Mazan, K., Nealon, E. and Van Nevel, J. (1993). The first 15 years: what has been learned about the Cancer Information Service and the implications for the future. Monographs of the National Cancer Institute, 14, 177-185.

Postmes, T., Spears, R. and Lea, M. (2000). The formation of group norms in computer-mediated communication. Human Communication Research, 26(3), 341371.

Sherman, D.A.K., Nelson, L.D. and Steele, C.M. (2000). Do messages about health risks threaten the self? Increasing the acceptance of threatening health messages via self-affirmation. Personality and Social Psychology Bulletin, 26(9), 1046-1058.

Snyder, C.R., Higgens, R.L. and Stucky, R.J. (1983). Excuses: masquerades in search of grace. New York: Wiley-Interscience.

Taylor, S. (1989). Positive illusions: creative self-deception and the healthy mind. New York: Basic Books.

Thelwell, M. (2001). Web log file analysis: backlinks and queries. ASLIB Proceedings, 53(6), 217-223.

Wallace, P. (1999). The Psychology of the Internet. Cambridge, UK: Cambridge University Press.

Walther, J.B. (1996). Computer-mediated communication: impersonal, interpersonal, and hyperpersonal interaction. Communication Research, 23(1), 3-43.

Wolf, A. (2000). Emotional expression online: gender differences in emoticon use. Cyberpsychology and Behavior, 3(5), 827-833.

\section{Acknowledgement}

The WWW data reported in Study Two was provided by Sally Tweddle, co-founder of the Cancerhelp website. Tragically, Sally died of cancer in 1999. We are indebted to her for her help and inspiration. 